\title{
Difference Equations and Discrete Dynamical Systems
}


This page is intentionally left blank 


\section{Difference Equations and \\ Discrete Dynamical Systems}

\section{Proceedings of the 9th International Conference}

University of Southern California, Los Angeles, California, USA $\quad 2-7$ August 2004

Editors

Linda J S Allen

Texas Tech University, USA

Bernd Aulbach

University of Augsburg, Germany

Saber Elaydi

Trinity University, USA

Robert Sacker

University of Southern California, Los Angeles, USA

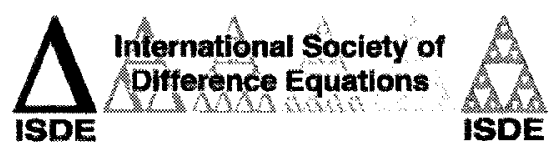

\section{No World Scientific}




\section{Published by}

World Scientific Publishing Co. Pte. Ltd.

5 Toh Tuck Link, Singapore 596224

USA office: 27 Warren Street, Suite 401-402, Hackensack, NJ 07601

UK office: 57 Shelton Street, Covent Garden, London WC2H 9HE

\section{British Library Cataloguing-in-Publication Data}

A catalogue record for this book is available from the British Library.

\section{DIFFERENCE EQUATIONS AND DISCRETE DYNAMICAL SYSTEMS Proceedings of the 9th International Conference}

Copyright $\odot 2005$ by World Scientific Publishing Co. Pte. Ltd.

All rights reserved. This book, or parts thereof, may not be reproduced in any form or by any means, electronic or mechanical, including photocopying, recording or any information storage and retrieval system now known or to be invented, without written permission from the Publisher.

For photocopying of material in this volume, please pay a copying fee through the Copyright Clearance Center, Inc., 222 Rosewood Drive, Danvers, MA 01923, USA. In this case permission to photocopy is not required from the publisher.

ISBN 981-256-520-5 


\section{Preface}

Difference Equations or Discrete Dynamical Systems is a diverse field which impacts almost every branch of pure and applied mathematics. Not surprisingly, the techniques that are developed vary just as broadly. The annual International Conference on Difference Equations and Applications is organized under the auspices of the International Society of Difference Equations. The Conferences have world wide attendance and cover a wide range of topics.

It is through this Proceedings that the mathematical community can (1) obtain an overview of all the presentations at the 9th International Conference on Difference Equations and Applications, (2) see a variety of problems and applications having one ingredient in common, the Discrete Dynamical System and (3) keep abreast of the many new techniques and developments in the area.

The emphasis of the meeting was on Mathematical Biology and accordingly about half of the presentations were in that area, Mathematical Ecology and Mathematical Medicine. 
This page is intentionally left blank 


\section{Contents}

Preface v v

A Discrete-Time Beverton-Holt Competition Model 1

Azmy S. Ackleh, Youssef M. Dib and Sophia R.-J. Jang

A Dynamic Analysis of the Bush Fiscal Policy

Richard H. Day and Chengyu Yang

A Hybrid Approximation to Certain Delay Differential Equation

with a Constant Delay

George Seifert

Compulsory Asymptotic Behavior of Solutions of Two-Dimensional

Systems of Difference Equations Josef Diblik and Irena Růžičková

Discrete Models of Differential Equations: The Roles of Dynamic

Consistency and Positivity

Ronald E. Mickens

Enveloping Implies Global Stability

Paul Cull

Global Asymptotic Stability in the Jia Li Model for Genetically

Altered Mosquitoes

Robert J. Sacker and Hubertus F. von Bremen

Global Behavior of Solutions of a Nonlinear Second-Order

Nonautonomous Difference Equation

Vlajko L. Kocic

How Can Three Species Coexist in a Periodic Chemostat?

Mathematical and Numerical Study

Shinji Nakaoka and Yasuhiro Takeuchi 
viii

Information-Theoretic Measures of Discrete Orthogonal Polynomials 135 Jesus Sanchez Dehesa, R. Álvarez-Nodarse, Pablo Sánchez-Moreno and R.J. Yáñez

Local Approximation of Invariant Fiber Bundles: An Algorithmic Approach

Christian Pötzsche and Martin Rasmussen

Necessary and Sufficient Conditions for Oscillation of Coupled

Nonlinear Discrete Systems

Serena Matucci and Pavel Řehák

Non-Standard Finite Difference Methods for Dissipative Singular 185 Perturbation Problems

Jean M.-S. Lubuma and Kailash C. Patidar

On a Class of Generalized Autoregressive Processes

Kamal C. Chanda

On $x_{n+1}=\frac{\beta_{n} x_{n}+\gamma_{n} x_{n-1}}{A_{n}+B_{n} x_{n}}$ with Period-Two Coefficients

Carol H. Gibbons and Carol B. Overdeep

Periodically Forced Nonlinear Difference Equations with Delay Abdul-Aziz Yakubu

Regularity of Difference Equations

Jarmo Hietarinta

Robustness in Difference Equations

Jack K. Hale

Solvability of the Discrete LQR-Problem under Minimal Assumptions

Roman Hilscher and Vera Zeidan

Some Discrete Competition Models and the Principle of

Competitive Exclusion

Jim M. Cushing and Sheree LeVarge 
Stability under Constantly Acting Perturbations for Difference 303 Equations and Averaging

Vladimir Burd

Symbolic Dynamics in the Study of Bursting Electrical Activity 313 Jorge Duarte, Jose Sousa Ramos and Luis Silva 